\title{
Miniplacas de ancoragem no tratamento da mordida aberta anterior
}

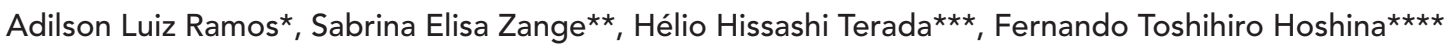

\begin{abstract}
Resumo
Introdução: o relato de caso apresentado descreve um tratamento ortodôntico auxiliado por miniplacas, de uma paciente adulta que apresentava mordida aberta anterior acentuada, rotação horária da mandíbula, biprotrusão e ausência de selamento labial. Após a extração dos primeiros molares e retração dentária superior e inferior, associada ao controle vertical propiciado pelas placas, ocorreu uma pequena rotação anti-horária da mandíbula e a correção da mordida aberta anterior, com significativa melhora facial. Objetivo: o presente relato corrobora as evidências atuais quanto à eficiência do uso de miniplacas de titânio como ancoragem temporária, especialmente em situações de correções de grande amplitude, envolvendo um problema vertical.
\end{abstract}

Palavras-chave: Miniplaca de ancoragem. Implantes de ancoragem. Exodontia de molares. Mordida aberta anterior. Biprotrusão.

\section{INTRODUÇÃO}

Dentre os últimos recursos tecnológicos incorporados na prática ortodôntica, destacam-se os dispositivos temporários de ancoragem ${ }^{2,5,11,14,17}$. Tanto os mini-implantes, nos seus diversos desenhos, como as miniplacas de titânio têm permitido ampliar a capacidade corretiva nos tratamentos compensatórios, bem como maior controle em mecânicas convencionais ${ }^{1,3,4,9}$. Particularmente, o tratamento da mordida aberta anterior com envolvimento esquelético foi, incontestavelmente, favorecido com estes novos recursos $3,7,17$.

A mordida aberta anterior esquelética (MAAE) pode envolver um desenvolvimento vertical alveo- lar posterior excessivo, um ramo mandibular curto, ângulo do plano mandibular aumentado, bem como altura facial anterior inferior aumentada, associada, freqüentemente, à falta de selamento labial passivo ${ }^{7}$. Diversos métodos ortopédico-ortodônticos têm sido relatados para a sua correção (AEB tração alta, Bite-blocks com e sem magnetos, Intruder, entre outras variações). Entretanto, diante de resultados modestos destes métodos, principalmente em pacientes adultos, a maioria dos casos acabava requerendo o auxílio da cirurgia ortognática para sua efetiva correção $0^{7,17}$.

Mediante o auxílio dos dispositivos temporários de ancoragem, tanto mini-implantes como

* Mestre em Ortodontia pela USP - Bauru/SP. Doutor em Ortodontia pela UNESP - Araraquara/SP. Professor Adjunto do Departamento de Odontologia da UEM. Coordenador da Pós-Graduação em Odontologia da Universidade Estadual de Maringá.

** Especialista em Ortodontia pela UEM.

*** Professor Adjunto do Departamento de Odontologia da Universidade Estadual de Maringá. Mestre e doutor em Ortodontia pela Faculdade de Odontologia de Araraquara - UNESP.

**** Especialista em Ortodontia pela Universidade Estadual de Maringá. 
miniplacas, a capacidade de correção não-cirúrgica destes casos aumentou razoavelmente. A literatura tem apresentado diversos casos de MAAE tratados com sucesso, diante deste novo horizonte terapêutico ${ }^{3,7,17}$. Além disso, a estabilidade das correções obtidas parece ser promissora ${ }^{16}$.

Embora os mini-implantes tenham melhorado

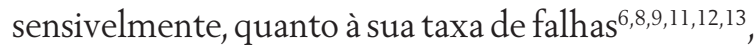
as miniplacas de ancoragem apresentam, até o presente momento, maior percentual de sucesso $^{3,10,16,17}$. Além disso, o fato de as miniplacas permanecerem fixadas longe das raízes dentárias permite liberdade de movimentação, sem necessidade de mudança de posição do dispositivo de ancoragem.

O presente artigo apresenta um relato de caso de MAAE que recebeu miniplacas de ancoragem para correção ortodôntica.

\section{RELATO DE CASO}

Uma paciente do gênero feminino compareceu à clínica do curso de especialização em Ortodontia da Universidade Estadual de Maringá, queixandose de alterações dentárias e faciais. Foram solicita- dos os registros ortodônticos iniciais, incluindo-se a telerradiografia lateral, panorâmica, periapicais, fotografias extra e intrabucais e modelos de gesso (Fig. 1, 2, 3).

A paciente apresentava MAAE com suas características típicas (trespasse vertical negativo, altura facial anterior aumentada, ângulo do plano mandibular aumentado, ausência de selamento labial passivo) associada a excessiva biprotrusão, relação dentária de Classe III e ausência do primeiro molar superior direito e do primeiro e terceiro molares superiores esquerdos.

Duas propostas de tratamento foram apresentadas. A primeira incluía a associação com a cirurgia ortognática para correção esquelética efetiva. Neste caso, seria realizada a trissegmentação da maxila, permitindo sua impacção posterior e correção da inclinação dos incisivos superiores. $\mathrm{Na}$ mandíbula, seriam realizadas a osteotomia sagital de redução, bem como genioplastia de avanço, com redução vertical. Previamente à cirurgia, seria utilizado o aparelho ortodôntico fixo para descompensação inferior (com indicação de exodontia prévia dos primeiros molares inferiores)
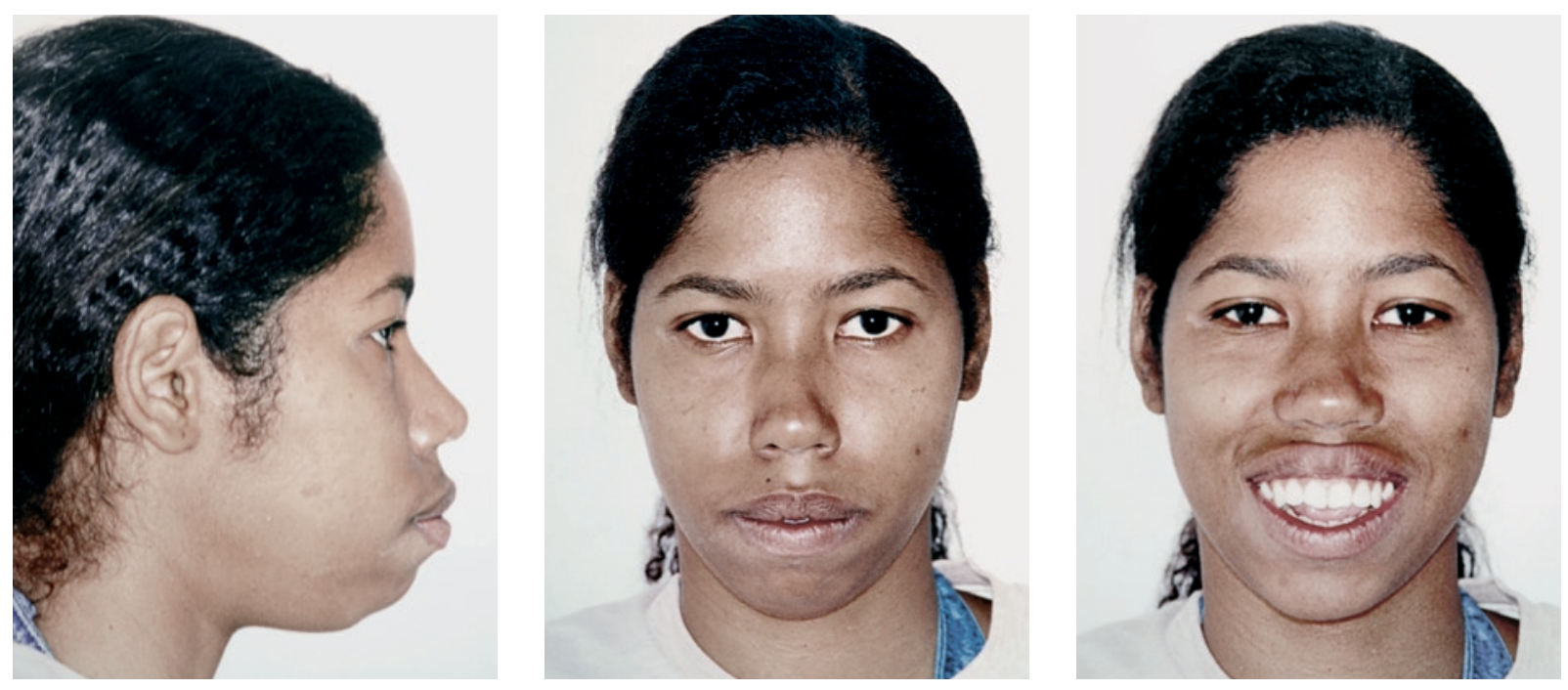

FIGURA 1 - Fotografias extrabucais pré-tratamento. 


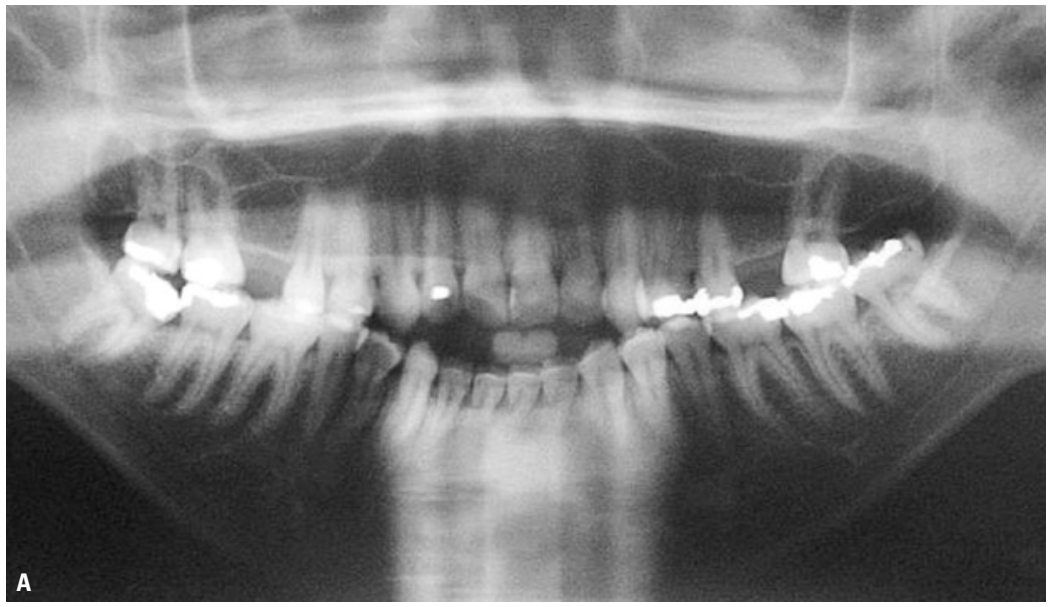

FIGURA 2 - A) Radiografias panorâmica e B) telerradiografia lateral pré-tratamento.
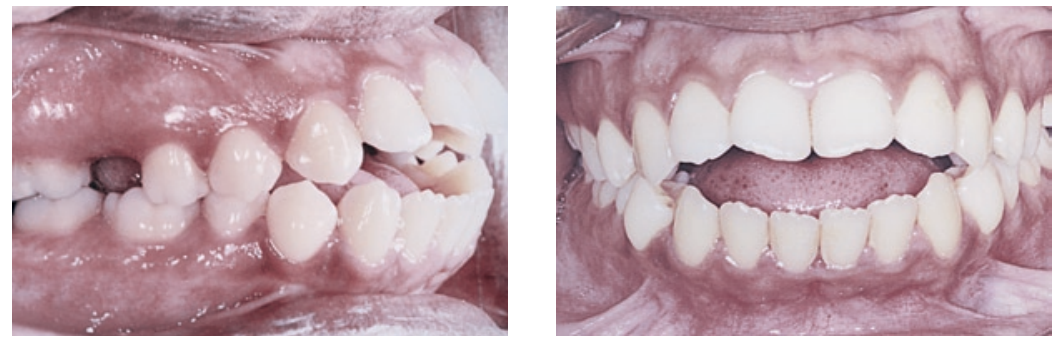

FIGURA 3 - Fotografias intrabucais pré-tratamento.

e nivelamento segmentado superior.

A segunda opção de tratamento incluía a correção compensatória, mediante o auxílio de 4 miniplacas de ancoragem (para permitir adequada correção da biprotrusão e controle vertical), também com indicação de exodontia dos primeiros molares inferiores.

Diante das opções oferecidas, a paciente preferiu o tratamento sem cirurgia ortognática, autorizando o tratamento devidamente esclarecido e consentido.

As placas de titânio utilizadas foram de modelo convencional, desenhadas originalmente para osteossíntese de cirurgia ortognática. As figuras 4 e 5 ilustram o procedimento da fixação
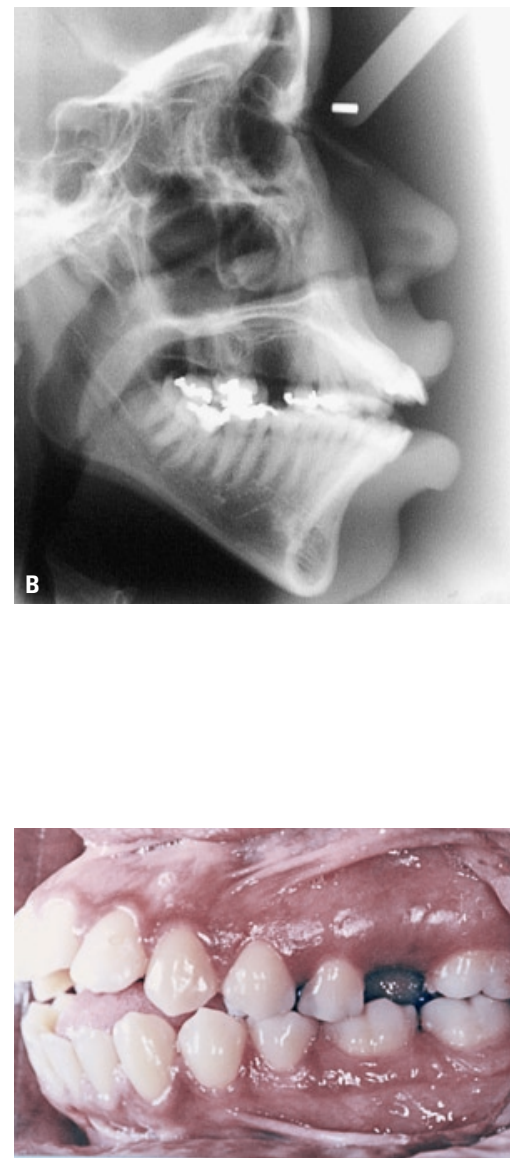

B 

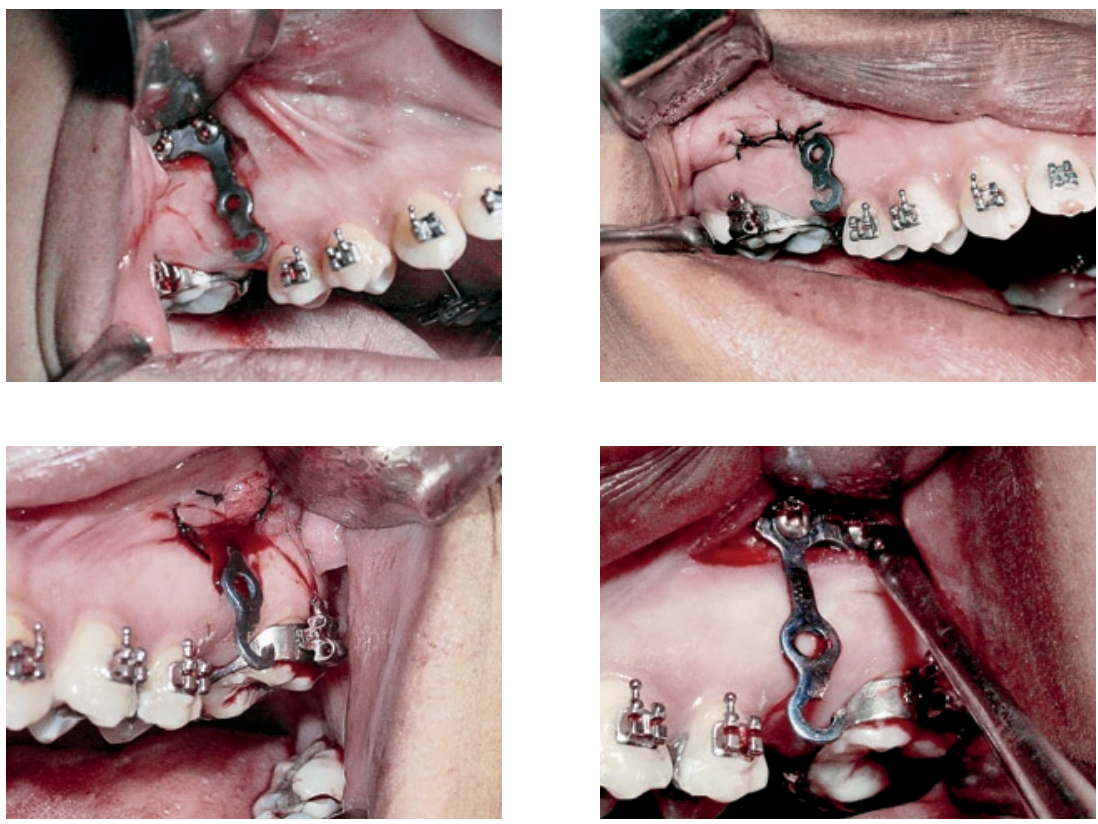

FIGURA 4 - Procedimentos cirúrgicos para instalação das miniplacas na maxila.
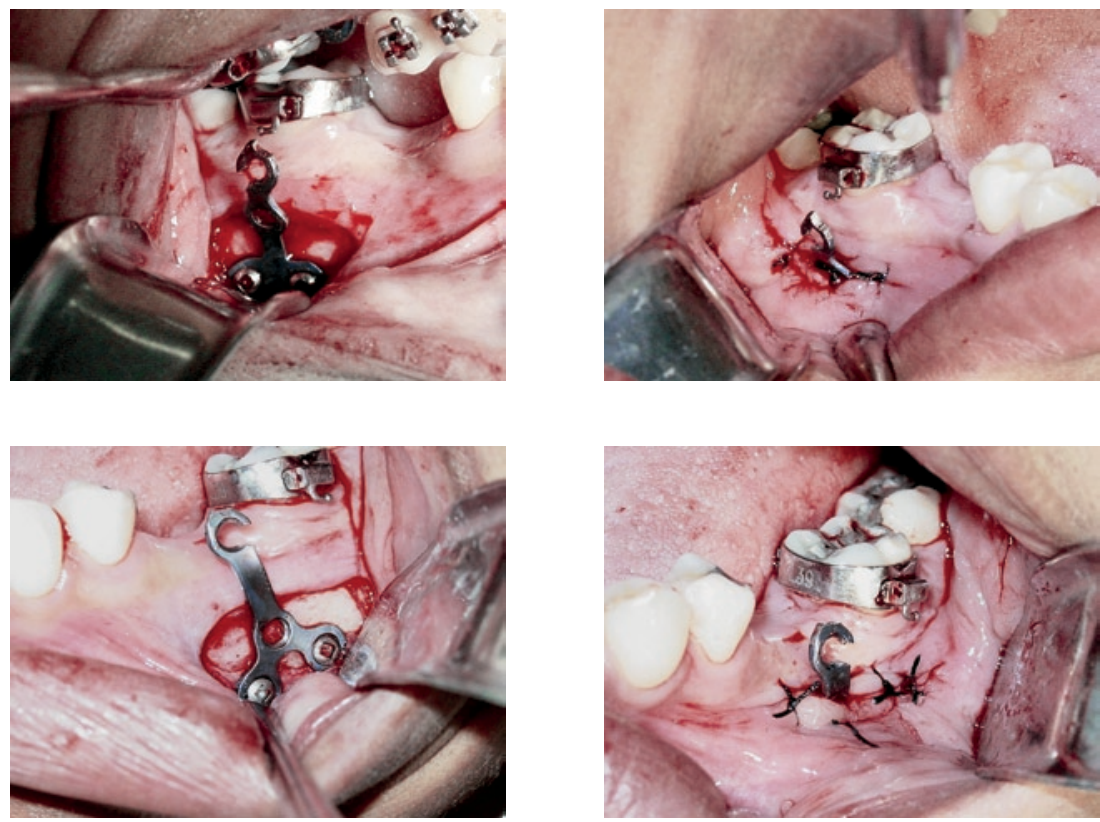

FIGURA 5 - Procedimentos cirúrgicos para instalação das miniplacas na mandíbula. 


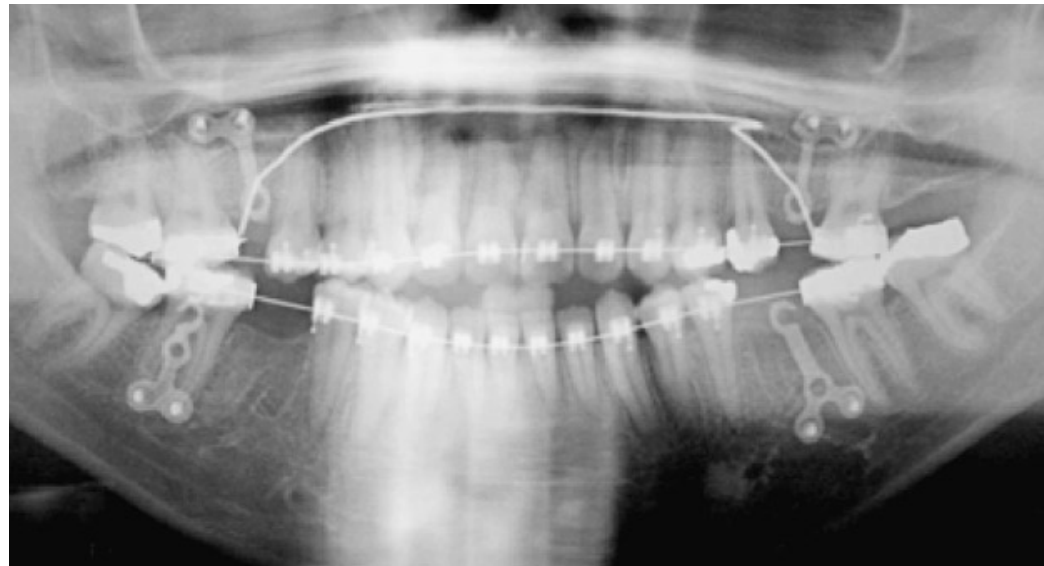

FIGURA 6 - Radiografia panorâmica após a instalação das miniplacas.

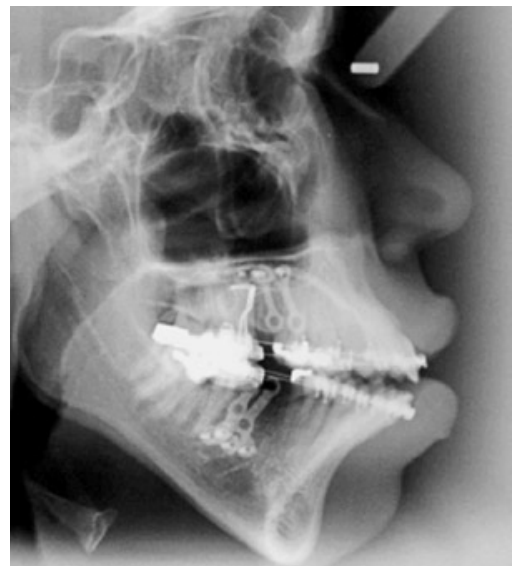

FIGURA 7 - Telerradiografia lateral após a instalação das miniplacas.
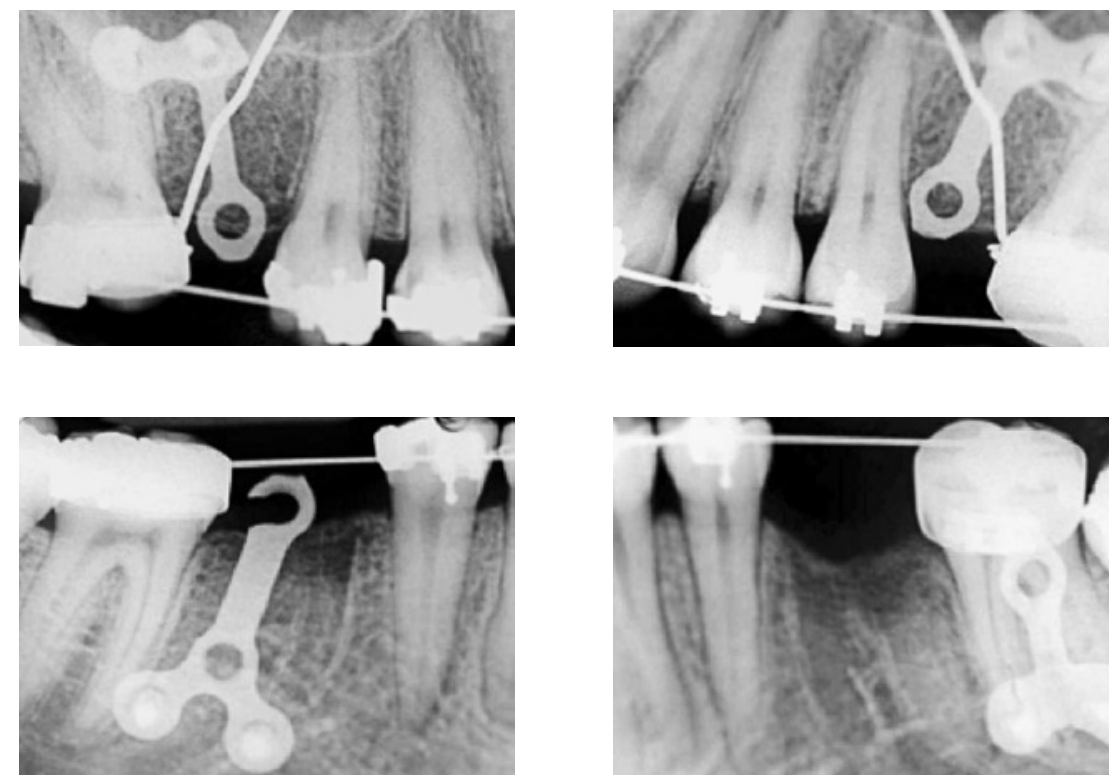

FIGURA 8 - Radiografias periapicais das regiões dos molares após a instalação das miniplacas.

a localização das miniplacas.

Nota-se na figura 9 que os últimos elos das placas superiores foram removidos, permitindo uma distância adequada em relação ao fio ortodôntico. No arco inferior, foi iniciada a retração dos segundos pré-molares, ancorando nas miniplacas.

Procedeu-se o alinhamento e nivelamento até o fio retangular, quando, então, foram soldados ganchos para a retração dos segmentos anteriores, associada ao controle vertical (especialmente superior), mediante o posicionamento das cadeias elastoméricas nas miniplacas. Como auxiliar de ancoragem superior, e com o objetivo de evitar a expansão do arco (devido ao vetor vertical), foi 

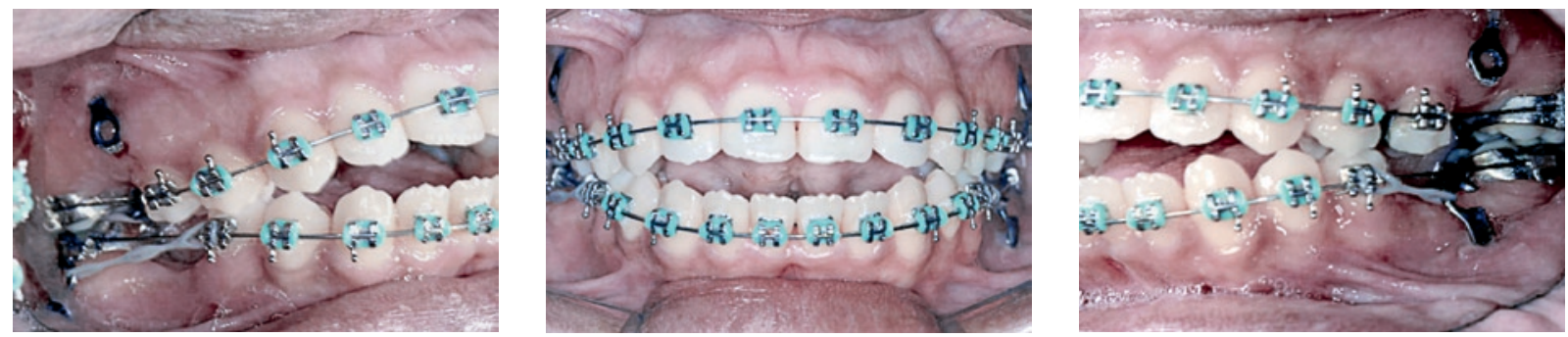

FIGURA 9 - Fase de nivelamento e alinhamento, iniciando-se a retração dos pré-molares inferiores. Nota-se que foram removidos os elos das miniplacas superiores que estavam mais próximos do fio. № arco superior foi utilizada uma barra palatina para evitar a expansão vestibular decorrente do vetor intrusivo.
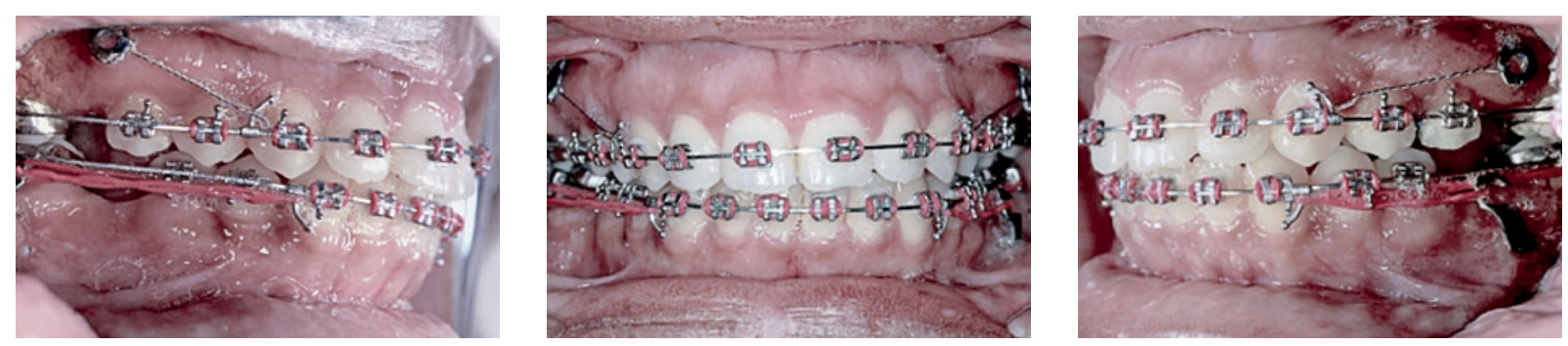

FIGURA 10 - Fase intermediária do tratamento, com retração superior provisoriamente estacionada e retração ântero-inferior acelerada, somada à mesialização dos molares inferiores.

utilizada uma barra palatina $0,8 \mathrm{~mm}$ encaixada nos segundos molares.

A figura 10 registra uma fase do tratamento em que a mordida aberta anterior já apresentava-se corrigida, os arcos na região anterior estavam em boa relação ântero-posterior, entretanto a mesialização dos molares inferiores estava menos evidente que a dos superiores. Por esta razão, a retração superior foi estacionada momentaneamente (estabilizada mediante um fio de amarrilho trançado de $0,10 \mathrm{~mm}$ ) e a movimentação dos inferiores foi acelerada com uma cadeia elastomérica que passava pela miniplaca e pelo gancho, até os molares.

As fotografias intermediárias ilustram uma parcial melhora facial, entretanto com aumento da exposição gengival (Fig. 11). A correção da protrusão dos incivisos superiores, mesmo com o controle vertical, provocou esta situação corriqueira, também salientada por Sarver e Ackerman ${ }^{15}$. Já que o grau de correção da mordida aberta anterior encontrava-se adequado e com sobre correção, optou-se pela inclusão de um arco auxiliar de intrusão do segmento anterior, concomitante à continuação da mecânica.

A figura 12 ilustra uma fase próxima do final do fechamento total dos espaços e a figura 13 ilustra a melhora sensível da face da paciente, influenciada pela correção da biprotrusão com o controle vertical, propiciados pelas miniplacas.

A sobreposição dos traçados cefalométricos do pré-tratamento e da fase de finalização ilustra as alterações obtidas (Fig. 14D).

As figuras 15, 16 e 17 apresentam comparações das fotografias extrabucais iniciais, intermediárias e finais frontais, sorrindo e de perfil, respectivamente.

Durante todo o período, a paciente não relatou sintoma de desconforto em relação às miniplacas de ancoragem. 

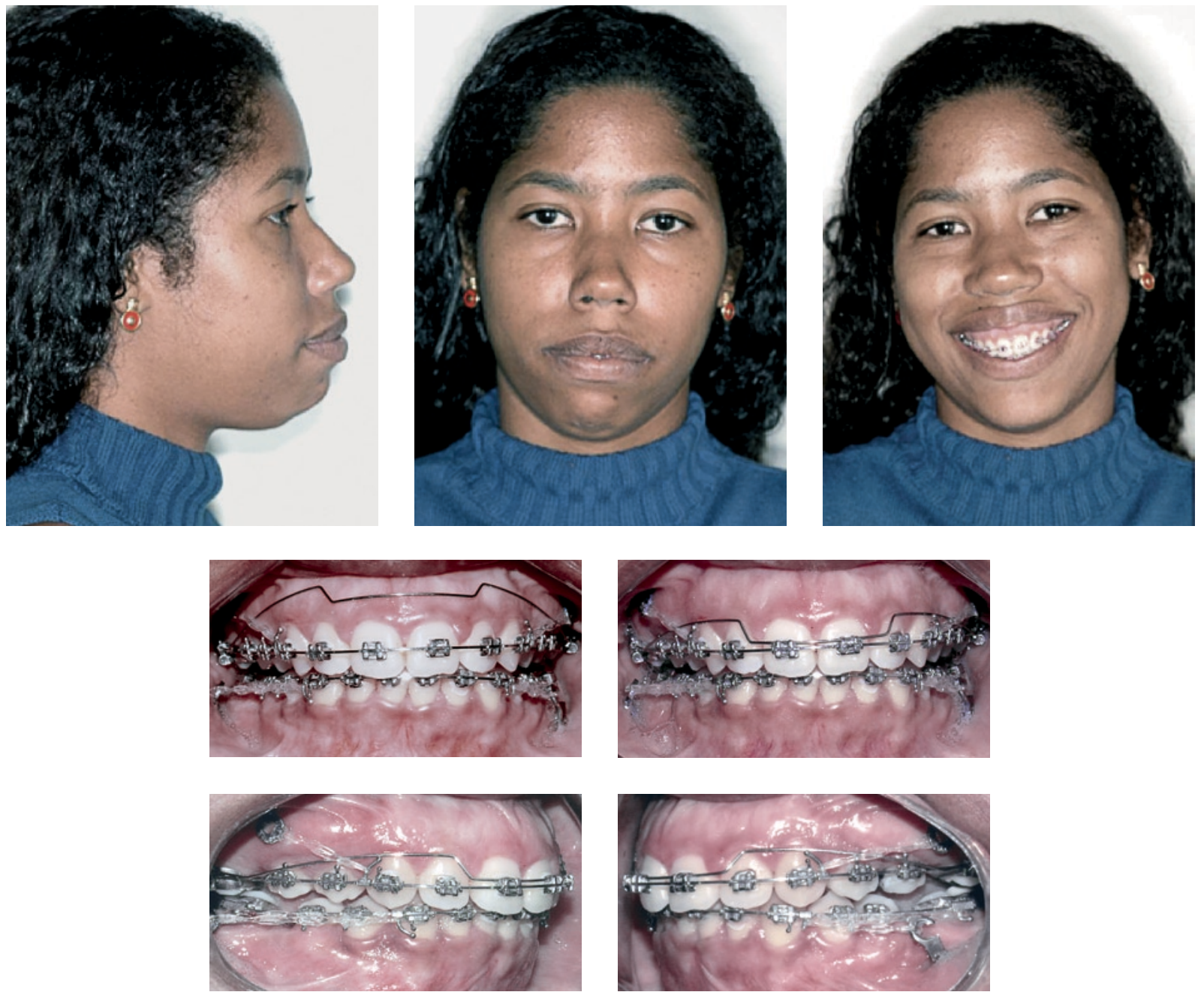

FIGURA 11 - Incorporação de um arco auxiliar de intrusão, para controle vertical anterior, minimizando a exposição gengival excessiva.
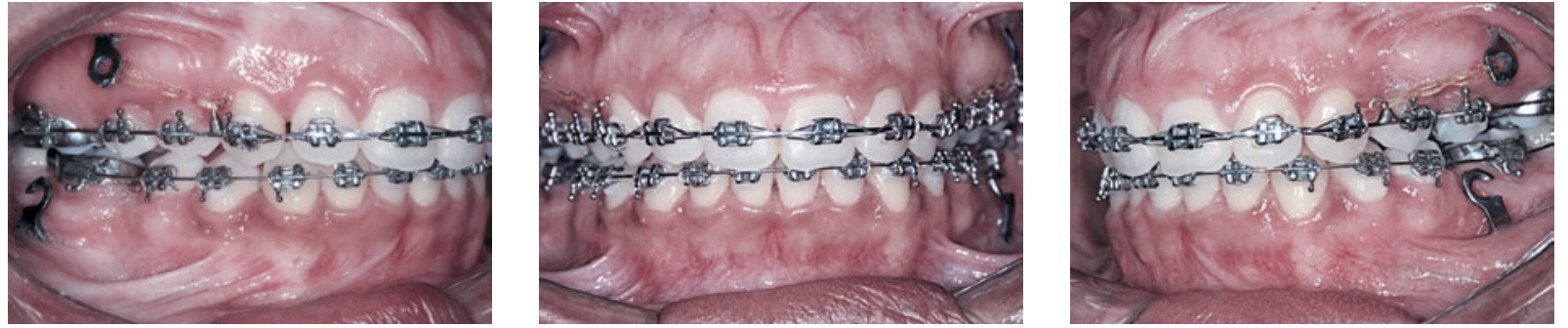

FIGURA 12 - Fotos intrabucais da fase final do tratamento. 

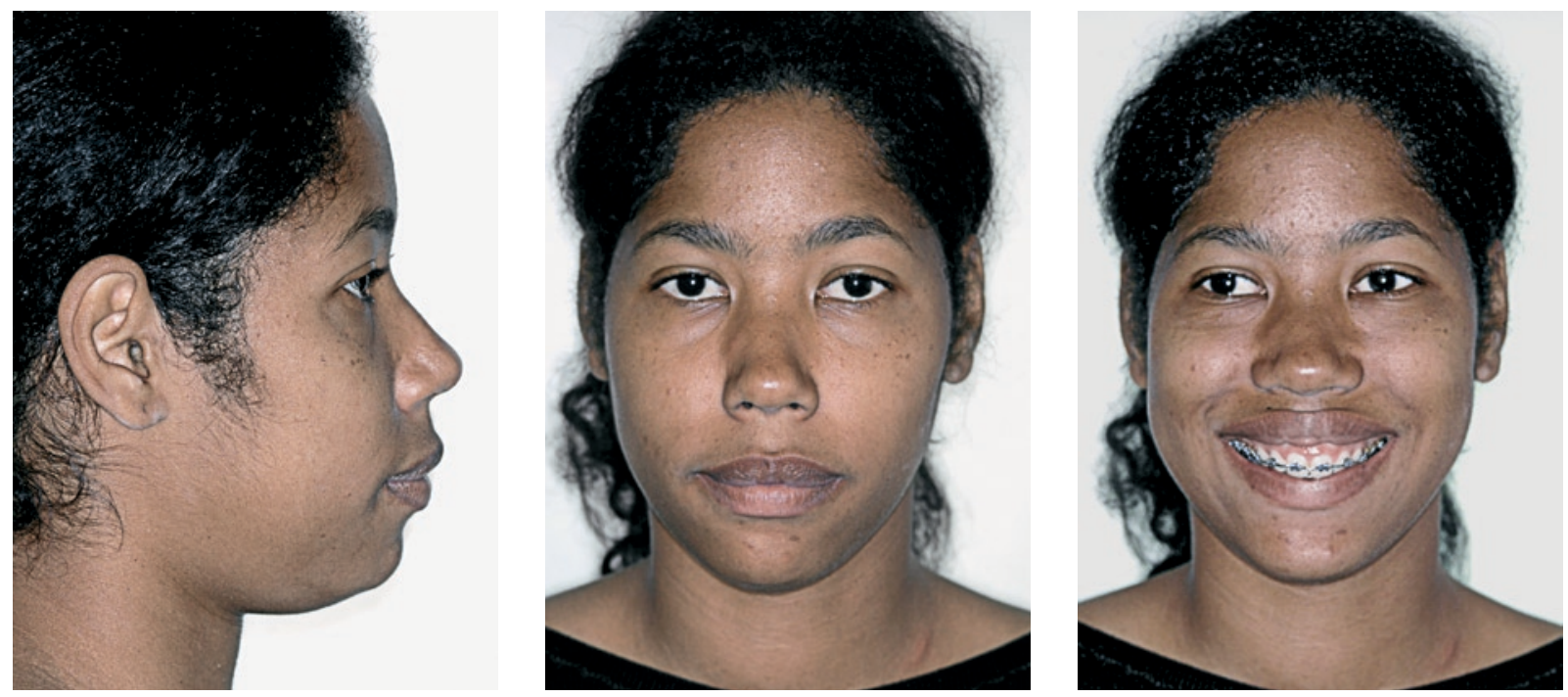

FIGURA 13 - Fotos extrabucais da fase final do tratamento. Nota-se uma sensível melhora do perfil facial.
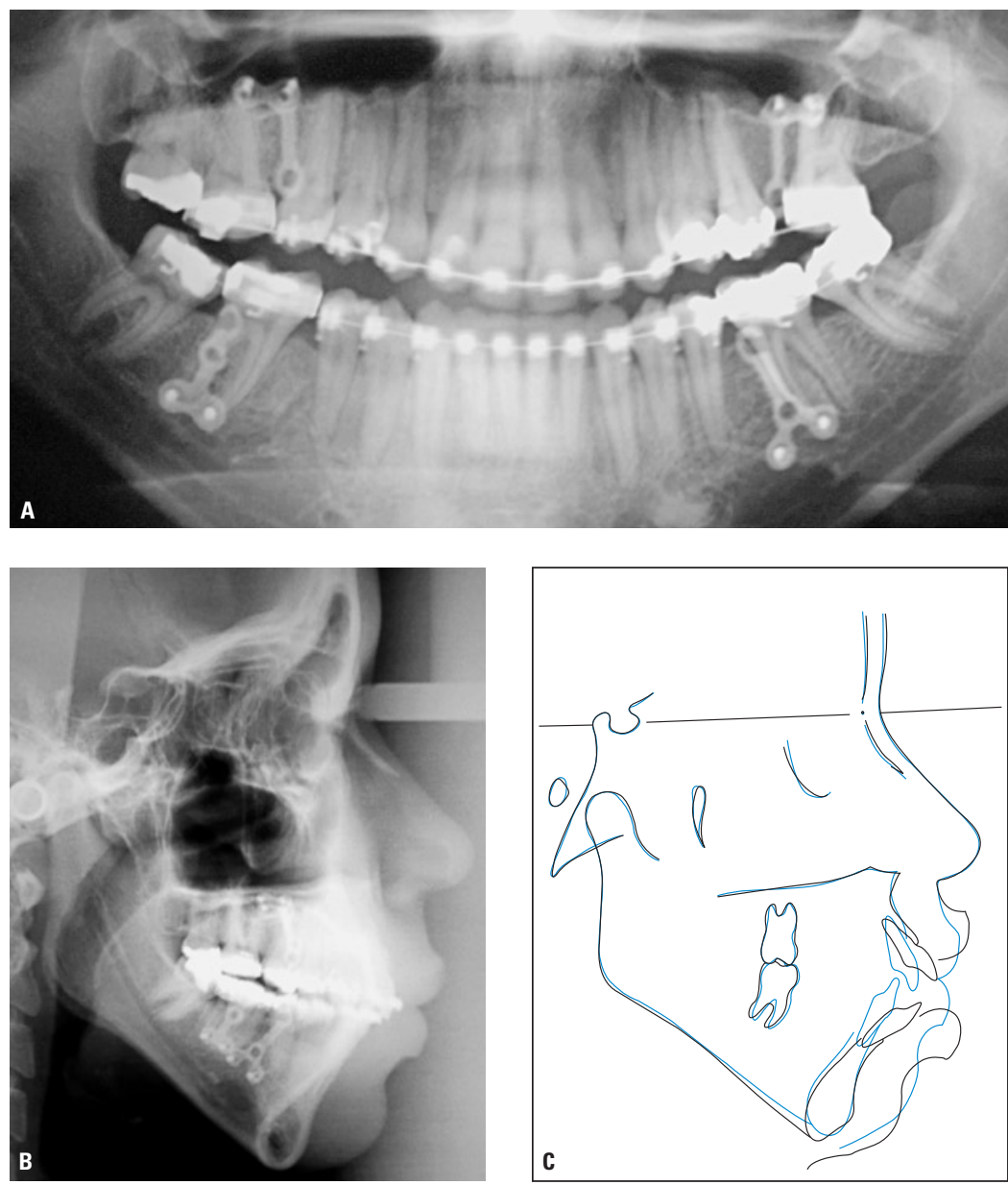

FIGURA 14 - Radiografias da fase de finalização: A) panorâmica e B) telerradiografia lateral. C) Sobreposição dos traçados inicial e da fase de finalização. 

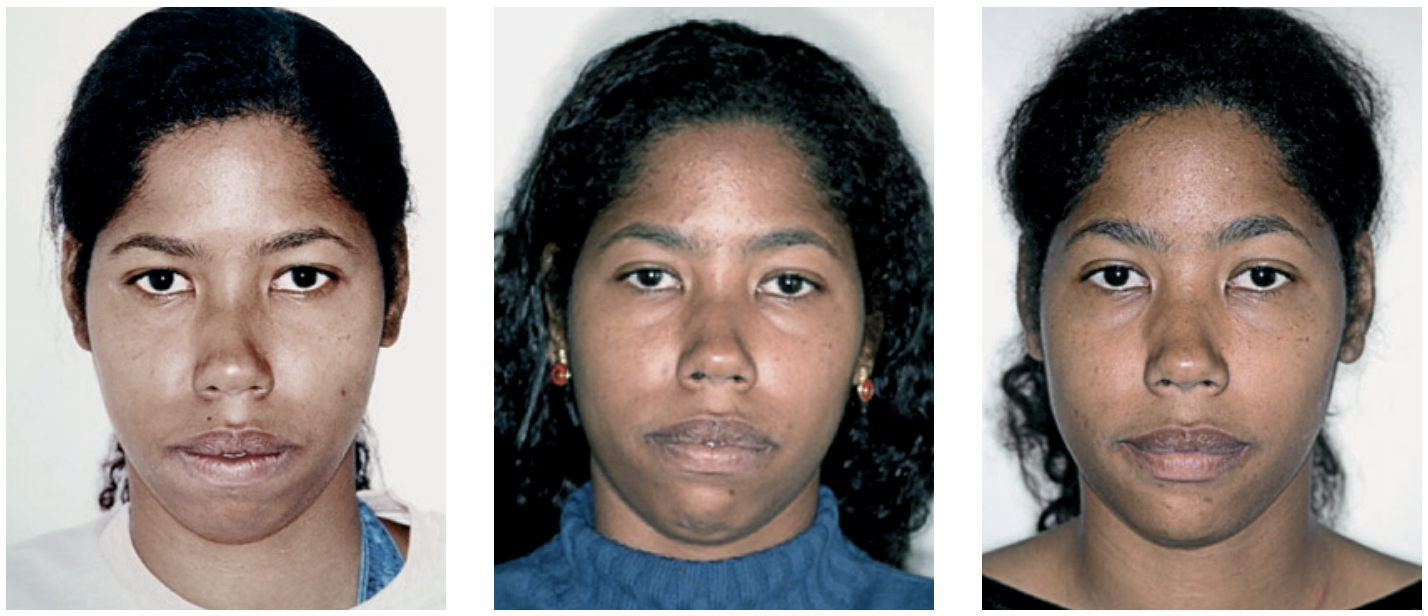

FIGURA 15 - Evolução do aspecto extrabucal frontal em repouso, do início até a fase de finalização.
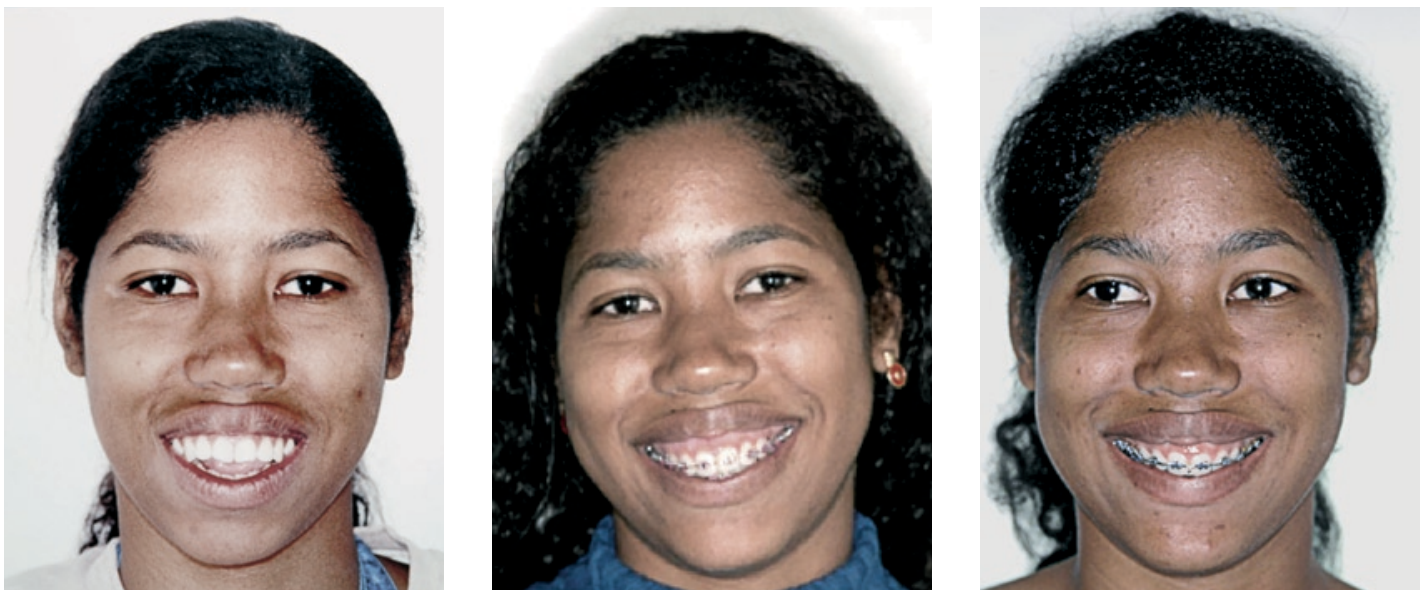

FIGURA 16 - Evolução do aspecto extrabucal frontal sorrindo, do início até a fase de finalização.
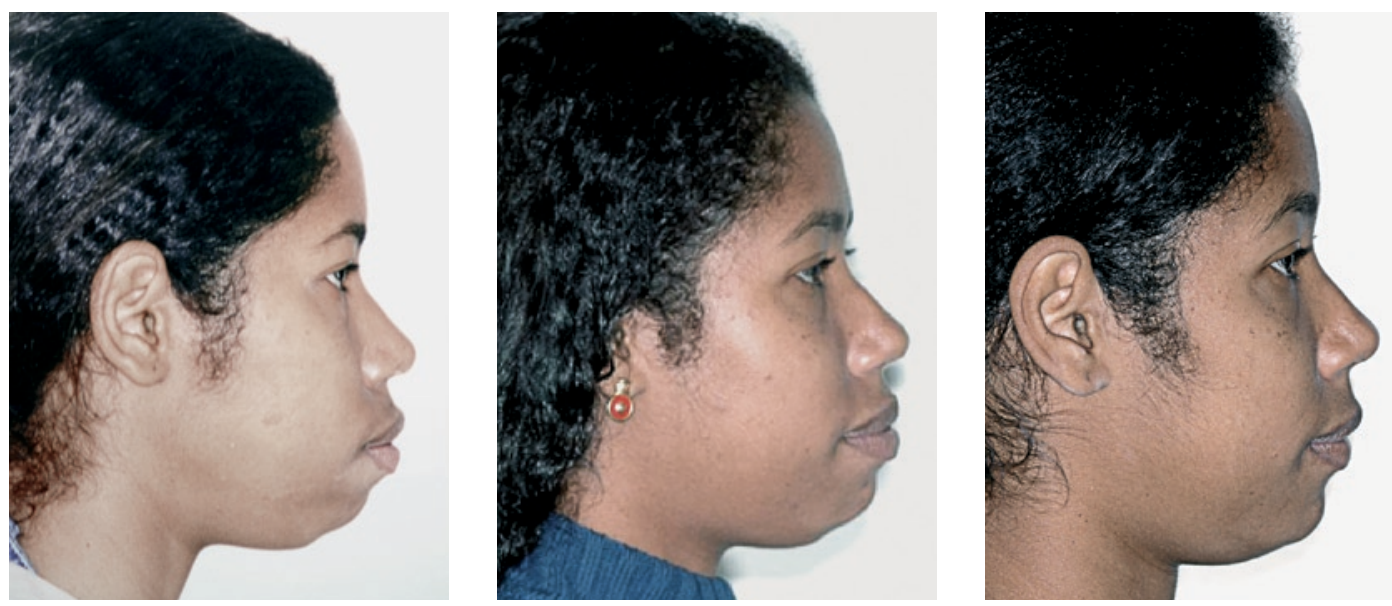

FIGURA 17 - Evolução do aspecto extrabucal lateral em repouso, do início até a fase de finalização. 


\section{CONCLUSÃO}

O presente relato corrobora as evidências atuais quanto à eficiência do uso de miniplacas de titânio como ancoragem temporária, especialmente em situações de correções de grande amplitude, envolvendo um problema vertical.

Enviado em: janeiro de 2008 Revisado e aceito: maio de 2008

\title{
Anchorage miniplates on anterior open-bite treatment
}

\begin{abstract}
Introduction: The case report presented describes an orthodontic treatment supported by miniplates of an adult female patient who presented severe anterior openbite, clockwise rotation of the mandible, biprotrusion and the absence of labial sealing. After extraction of first molars and maxillary and mandibulary dental retraction, associated with vertical control provided by the miniplates, the anterior openbite was corrected with a little anti-clockwise rotation, resulting in a significant improve on facial appearance. Aim: This case report confirms the efficiency of titanium miniplates as temporary anchorage, especially in situations where great corrections are needed, involving a vertical problem.
\end{abstract}

Key words: Anchorage miniplates. Anchorage implants. Molar extraction. Anterior open bite. Biprotrusion.

\section{REFERÊNCIAS}

1. ARAÚJO, T. M.; NASCIMENTO, M. H. A.; BEZERRA, F.; SOBRAL, M. C. Ancoragem esquelética em Ortodontia com miniimplantes. Rev. Dental Press Ortodon. Ortop. Facial, Maringá, v. 11, n. 4, p. 126-156, jul./ago. 2006.

2. CREEKMORE, T. D.; EKLUND, M. K. The possibility of skeletal anchorage. J. Clin. Orthod., Boulder, v. 17, no. 4, p. 266-269, 1983.

3. FABER, J. Ancoragem esquelética com miniplacas. In: LIMA FILHO, R. A.; BOLONHESE, A. M. Ortodontia: arte e ciência. 1. ed. Maringá: Dental Press, 2007.

4. JANSON, M. Ancoragem esquelética com miniimplantes: incorporação rotineira da técnica na prática ortodôntica. Rev. Clin. Ortodon. Dental Press, Maringá, v. 5, n. 4, p. 85-100, 2006.

5. KANOMI, R. Mini-implant for orthodontic anchorage. J. Clin. Orthod., Boulder, v. 31, no. 11, p. 763-767, Nov. 1997.

6. KIM, J. W.; AHN, S. J.; CHANG, Y. I. Histomorphometric and mechanical analyses of the drill-free screw as orthodontic anchorage. Am. J. Orthod. Dentofacial Orthop., St. Louis, v. 128, no. 2, p. 190-194, 2005.

7. KURODA, S.; KATAYAMA, A.; TAKANO-YAMAMOTO, T. Severe anterior open-bite case treated using titanium screw anchorage. Angle Orthod., Appleton, v. 74, no. 4, p. 558-567, 2004.

8. LIOU, E. J.; PAI, B. C.; LIN, J. C. Do miniscrews remain stationary under orthodontic forces? Am. J. Orthod. Dentofacial Orthop., St. Louis, v. 126, no. 1, p. 42-47, 2004.

9. MARASSI, C. Quais as principais aplicações clínicas atuais e quais as chaves para o sucesso dos miniimplantes em Ortodontia? Rev. Clin. Ortodon. Dental Press, Maringá, v. 5, n. 4, p. 13-25, 2006

10. MYAWAKI, S.; KOYAMA, I.; INOUE, M.; MISHIMA, K.; SUGAHARA, T.; TAKANO-YAMAMOTO, T. Factors associated with the stability of titanium screws placed in the posterior region for orthodontic anchorage. Am. J. Orthod. Dentofacial Orthop., St. Louis, v. 124, no. 4, p. 373-378, 2003.
11. PARK, H. S.; BAE, S. M.; KYUNG, H. M.; SUNG, J. H. Microimplant anchorage for treatment of skeletal Class I bialveolar protrusion. J. Clin. Orthod., Boulder, v. 35, no. 7, p. 417-422, 2001.

12. PARK, H. S. An anatomical study using $C T$ images for the implantation of micro-implants. Korean J. Orthod., Korea, v. 32, no. 6, p. 435-441, 2002.

13. POGGIO, A. P. M.; INCORVATIB, C.; VELOB, S.; CARANO, A. "Safe zones': a guide for miniscrew positioning in the maxillary and mandibular arch. Angle Orthod., Appleton, v. 76, no. 2, p. 191-197, Mar. 2006.

14. ROBERTS, W. E.; HELM, F. R.; MARSHALL, K. J.; GONGLOFF, R. K. Rigid endosseous implants for orthodontic and orthopedic anchorage. Angle Orthod., Appleton, v. 59, no. 4 p. 247-256, Winter 1989.

15. SARVER, D. M.; ACKERMAN, M. B. Dynamic smile visualization and quantification: Part 2. Smile analysis and treatment strategies. Am. J. Orthod. Dentofacial Orthop., St. Louis, v. 124 , no. 2 , p. 116-127.

16. SUGAWARA, J. et al. Treatment and posttreatment dentoalveolar changes following intrusion of mandibular molars with application of a skeletal anchorage system (SAS) for open bite correction. Int. J. Adult. Orthodon. Orthognath. Surg., Chicago, v. 17, no. 4, p. 243-253, 2002.

17. UMEMORI, M.; SUGAWARA, J.; MITANI, H.; NAGASAKA,

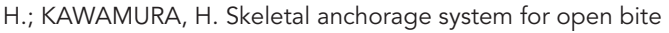
correction. Am. J. Orthod. Dentofacial Orthop., St. Louis, v. 115 , no. 2, p. 166-174, Feb. 1999.

Endereço para correspondência

Adilson Luiz Ramos

Rua Arthur Thomas 831

CEP: 87.013-250 - Maringá/PR

E-mail: alramos@ortodontista.com.br 